\title{
Meio ambiente e desenvolvimento
}





\title{
Energia como fator limite para o desenvolvimento sustentável
}

\author{
JOSÉ ISR AEL VARGAS
}

$\mathrm{O}$

TÍTULO DESTA COMUNICAÇ̃̃o, há alguns anos atrás, poderia constituir uma declaração chocante face às teorias de desenvolvimento sócio-econômico correntes e/ou dominantes então.

Na verdade, tendo em mente a mais elementar definição de energia como sendo a capacidade de produzir trabalho, até recentemente era óbvio considerar o progresso material e social da humanidade como resultado direto do aumento da intensidade do uso de energia, começando pela muscular (humana e animal), de água, vento e, mais tarde, de energias termais, sucessivamente de biomassa e combustíveis fósseis.

Toda a textura e estrutura da sociedade humana, de fato, atesta o aumento de um milhão de vezes na intensidade de fontes de energia primária - começando com cerca de algumas centenas de eletrovolts, característica das fontes mencionadas, passando por alguns eletrovolts típicos de energia química (combustão), para chegar a centenas e assim a milhões de eletrovolts associados à fissão de urânio.

Talvez um parêntese do que se tornará explícito mais adiante deveria afirmar de imediato que a energia como fator limite para o desenvolvimento sustentável é a combinação de quatro fatores:

- desigual distribuição geográfica e, portanto, geopolítica, do consumo de energia;

- crescimento da população;

- aceleração na intensidade da utilização de energia;

- crescimento constante de 2 ou 3\% do uso de energia, predominante nos últimos 120 anos (figuras l e 2); apesar do considerável e por vezes espetacular aumento na eficiência da produção e do uso de energia, que estabeleceu os limites para um desenvolvimento sustentável, explícito no título desta apresentação.

De fato, valeria lembrar que, segundo o Conselho Mundial de Energia (1), 
o consumo no mundo chegou, em 1990, ao equivalente a 8.7 gigatons de óleo, o que pressupõe atingir entre 11.2 e 17.2 gigatons em 2020, dependendo:

- do papel de uma influência maior na preocupação ambiental e política pertinente;

- da evolução da eficiência na produção e utilização de energia;

- e, naturalmente, do índice observado do desenvolvimento econômico mundial.

\section{G.W. Anos}

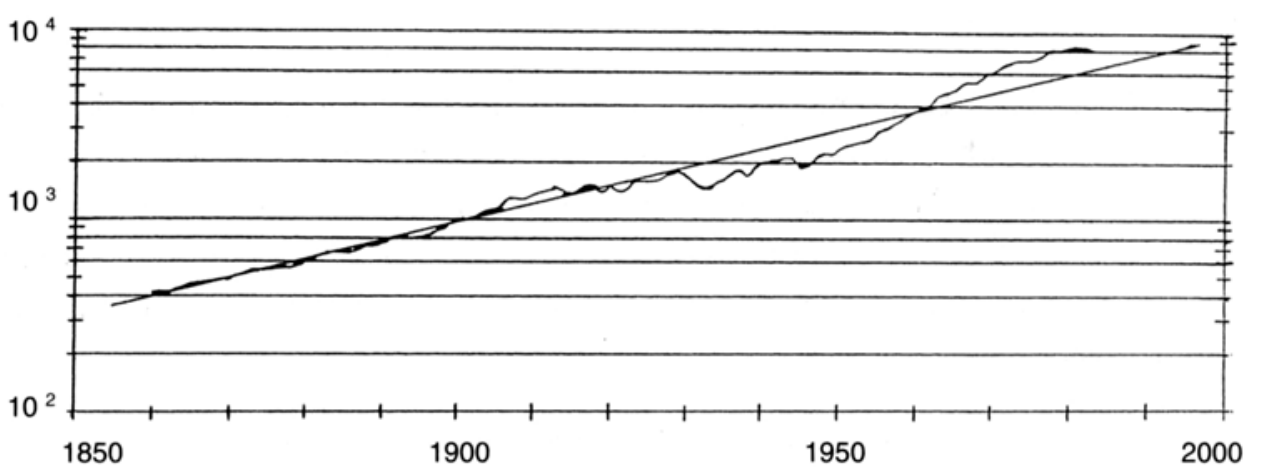

Figura 1

120 anos de uso de energia no mundo

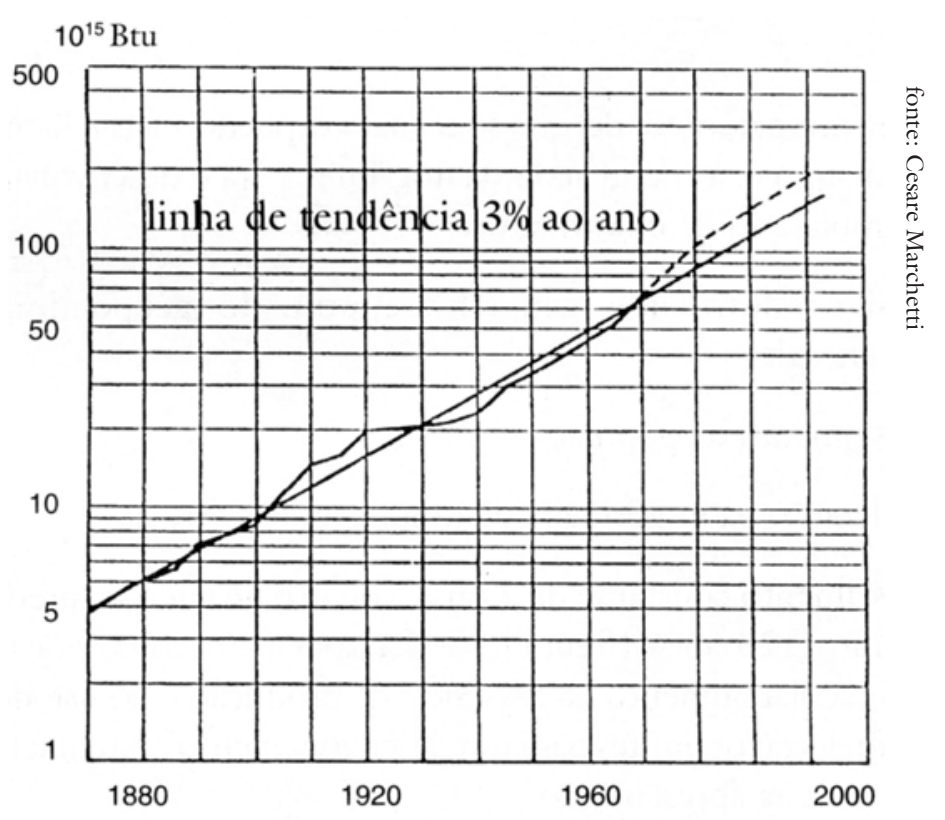

Figura 2

Total de consumo de energia nos EUA 
A parte maior dessa demanda futura será dos países em desenvolvimento, que aumentarão de 2.9 gigatons em 1990 para entre 6.3 e 10.3 em 2020. Essa evolução extraordinária na demanda nos países em desenvolvimento (de 110 a $250 \%$ ) originar-se-ia principalmente no crescimento futuro da população que, de acordo com as projeções das Nações Unidas, deveria chegar a cerca de 8.3 bilhões de pessoas em 30 anos, comparadas com os 5.3 bilhões de habitantes do planeta em 1990. Sabe-se também que $90 \%$ desse crescimento populacional estará concentrado nos países em desenvolvimento.

De acordo com o Conselho Mundial de Energia, o consumo no mundo industrializado deverá se estabilizar no nível atual, ou mesmo sofrer uma redução de $10 \%$ antes do ano 2020 .

Assim, nos próximos 30 anos, a situação nos países mais pobres poderá tornar-se crítica, tanto pelo provável custo quanto pelas dificuldades de acesso a fontes convencionais ou outras mais apropriadas ou ambientalmente mais benignas.

Um estudo especial sobre a eficiência e conservação de energia no mundo em desenvolvimento, feito pelo Banco Mundial (2), mostra que, para esses países, a eficiência de energia no consumo do setor industrial é de cerca $2 / 3$ ou $50 \%$ menor que o dos países industrializados, o que agrava ainda mais esse quadro.

De fato, a evolução na eficiência da transformação e uso de energia nos países industrializados, conforme figuras 3 e 4, tem evitado que se antecipe a ruptura ambiental global induzida pela energia, apesar de seu uso muito mais elevado.

A conclusão a que se chega, graças ao grande número de informações coletadas em anos recentes, indica que somente esforços a bem da eqüidade, para propiciar maior acesso à energia no mundo em desenvolvimento, acoplados a mudanças profundas nos estilos de vida dos países industrializados, levando à redução drástica imediata da taxa do uso de energia com algum tipo de nivelamento nas próximas décadas, inverterão os impactos ambientais perniciosos e possivelmente catastróficos que prejudicarão a possibilidade de desenvolvimento sustentável. A sustentabilidade consiste basicamente na adoção, pela sociedade, de um estilo de vida com tal contenção que preserve a diversidade dos sistemas de vida, levando a garantir a operação continuada do processo evolutivo multifacetado.

A concepção de sustentabilidade elaborada por um cientista natural foi minuciosamente discutida recentemente por Hans Peter Dürr (3), mas não será tratada aqui.

A prevenção antecipada dos efeitos do uso indiscriminado da energia no presente e no futuro implica: 
- aumento de uso de energia renovável - dos atuais 0.2 gigatons em 1990 para 15 gigatons em 2020, cresceendo sua participação na matriz da energia mundial dos atuais $2.5 \%$ para $13 \%$;

- conservação de energia;

- maior eficiência de energia.

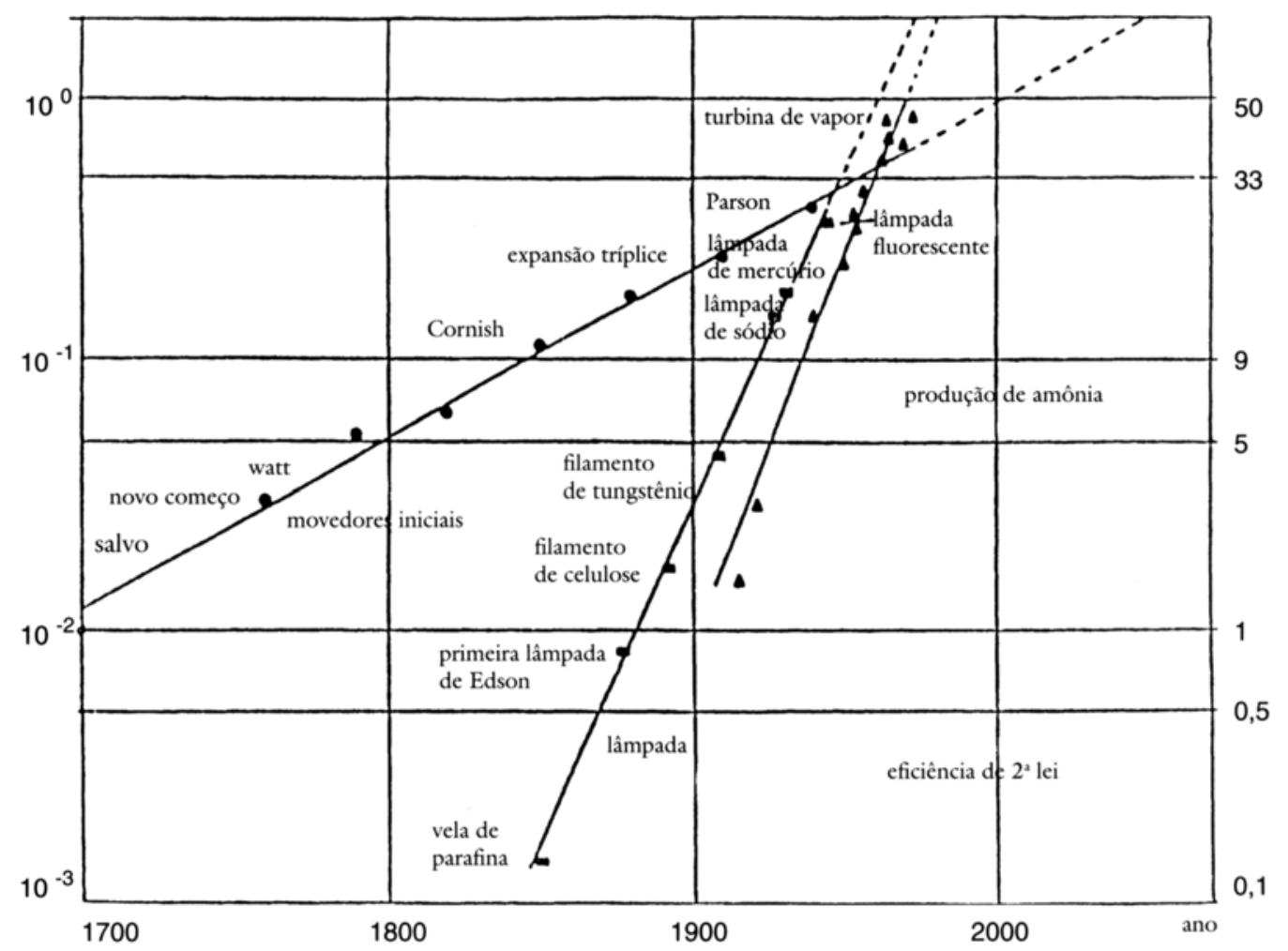

Figura 3: Tendências históricas em eficiência

De qualquer maneira, estudos também indicam que provável e, infelizmente, nos próximos 30 anos, de 63 a 75\% do mercado mundial de energia ainda será suprido por combustíveis fósseis, com pequena variação da oferta atual de $77 \%$.

Outros panoramas têm sido propostos para tratar dessa importante questão, como os discutidos por Goldemberg (4) e colaboradores, os quais certamente serão atualizados na comunicação que fará neste encontro.

A falha na implementação de modificações mais profundas que se tornam imprescindíveis foi discutida em muitos estudos e constitui sérios obstáculos para o desenvolvimento sustentável. 


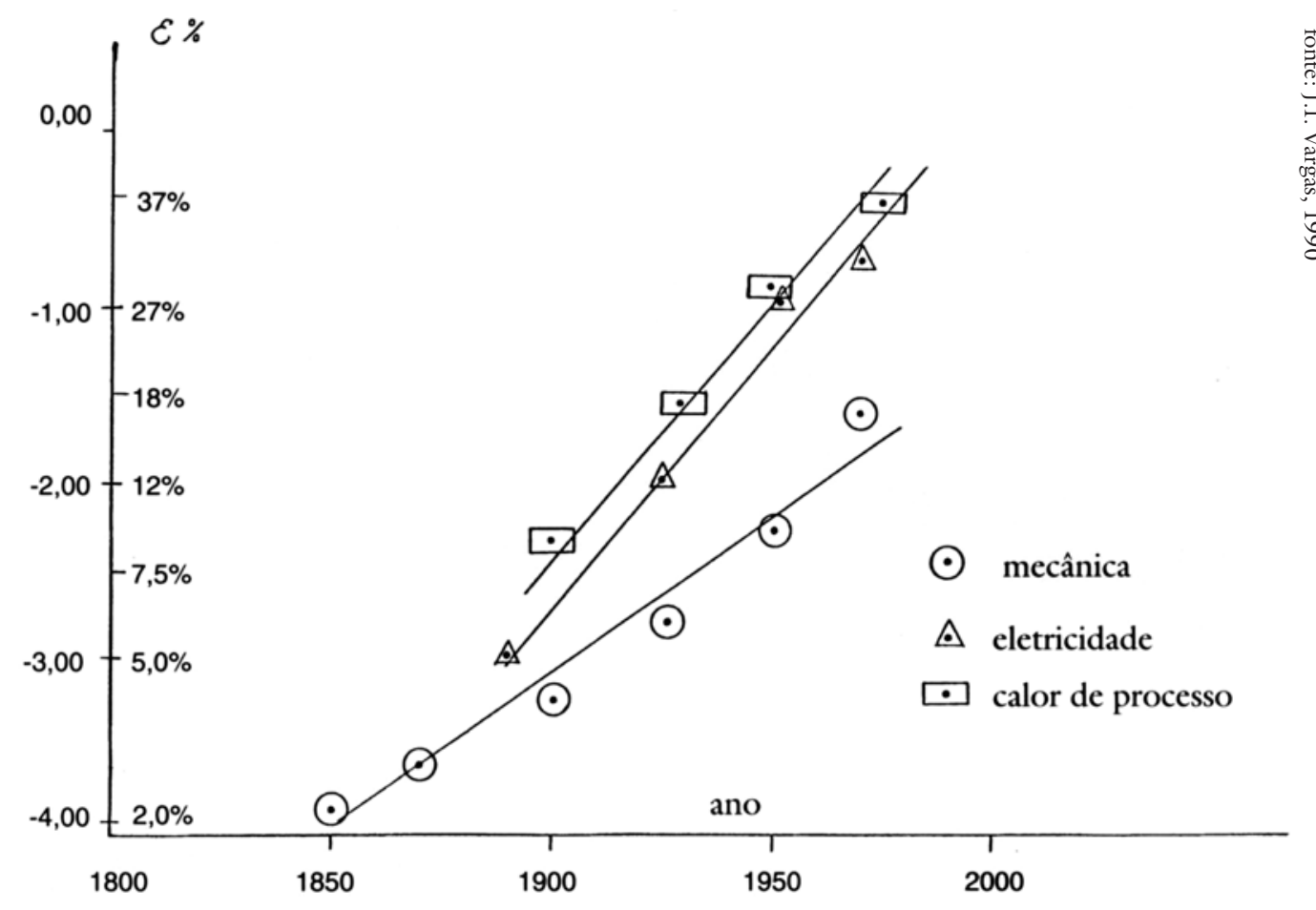

Figura 4

Evolução da eficiência da transformação de energia

Os combustíveis fósseis já são suficientemente reconhecidos como responsáveis por alterações globais nos sistemas de sustentação de vida. O tempo previsto para seu dano irreversível - se a atual taxa de utilização de energia for mantida - é, contudo, objeto ainda de muitos debates. Estes surgem principalmente por falta de informação quantitativa quanto à extensão e importância de $\mathrm{CO}_{2}$ e de outras bacias de gases de estufas antropogênicas, bem como das incertezas quanto aos mecanismos de trabalho - linear ou não-linear - afetando as interações complexas resultantes de ações humanas, particularmente no uso de energia, que ainda não permitem a formulação de modelos previsíveis razoavelmente precisos.

A quantificação de variações de emissão de $\mathrm{CO}_{2}$ na atmosfera é variável para períodos que cobrem os últimos 100 mil anos via medição da composição de bolhas de ar presas em geleiras (figura 5) ou por meio de análise $14 \mathrm{C}$ e $13 \mathrm{C}$ de três anéis (figura 6).

Ambos mostram valores crescentes para $\mathrm{CO}_{2}$ na atmosfera, mas emissões realmente resultantes de combustíveis fósseis queimando tornaram-se dominantes somente nas últimas cinco décadas. 


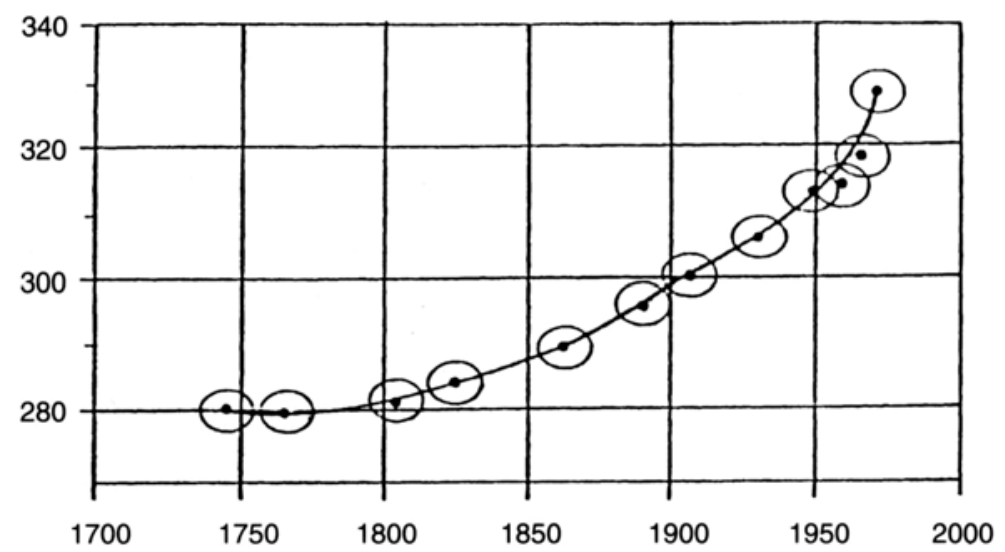

Séries históricas de concentração de $\mathrm{CO}_{2}$ no ar podem ser produzidas hoje, observando bolhas de ar presas em geleiras. Essa metodologia permite voltar a talvez 100.000 anos e comparar os níveis de $\mathrm{CO}_{2}$ com situações climáticas prevalentes, que podem ser avaliadas por vários tipos de análises de sedimentos (e três anéis para os últimos 150 anos). Essa reconstrução pode ajudar a calibrar os modelos climáticos, sobre os quais está baseada muito da controvérsia sobre $\mathrm{CO}_{2}$.

Figura 5: Medições de $\mathrm{CO}_{2}$ de bolhas de geleiras

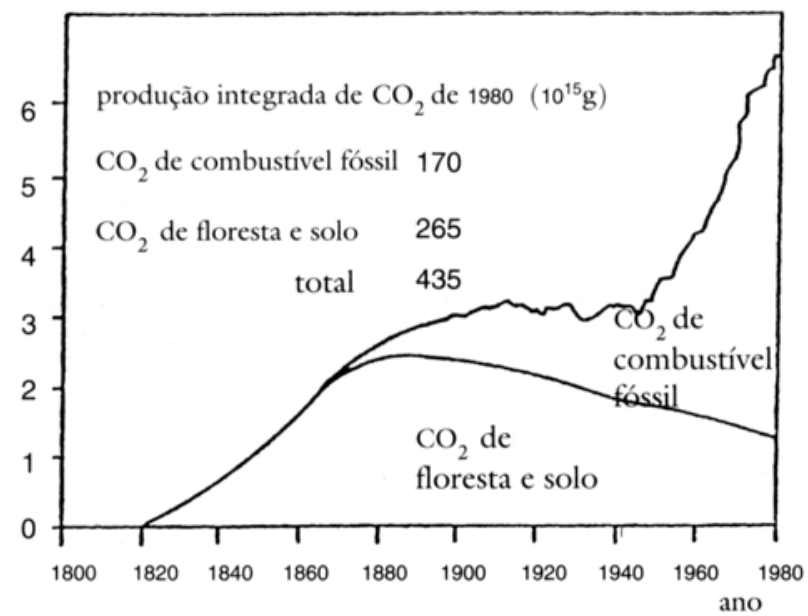

$\mathrm{O}$ conhecimento das emissões de $\mathrm{CO}_{2}$ fóssil e a análise dos três anéis para 14C e 13C permitem uma razoável reconstrução da quantidade de $\mathrm{CO}_{2}$ colocada na atmosfera pelas mudanças no nível de estocagem de carbono em florestas vivas e solo. Desses cálculos parece que a quantidade de $\mathrm{CO}_{2}$ integrada que sobrecarrega os níveis de $\mathrm{CO}_{2}$ no ar é devida mormente a atividades relacionadas com a agricultura e florestas. Somente após a Segunda Guerra Mundial as emissões de combustíveis fósseis se tornaram predominantes.

Figura 6: Produção anual de $\mathrm{CO}_{2}\left(10^{9}\right.$ toneladas de $\left.\mathrm{CO}_{2}\right)$ 
É também possível quantificar a média de aumentos de temperatura da terra, por longos períodos, como se vê nas figuras 7 e 8 , mas sem dúvida o nível de incertezas é ainda bastante alto.

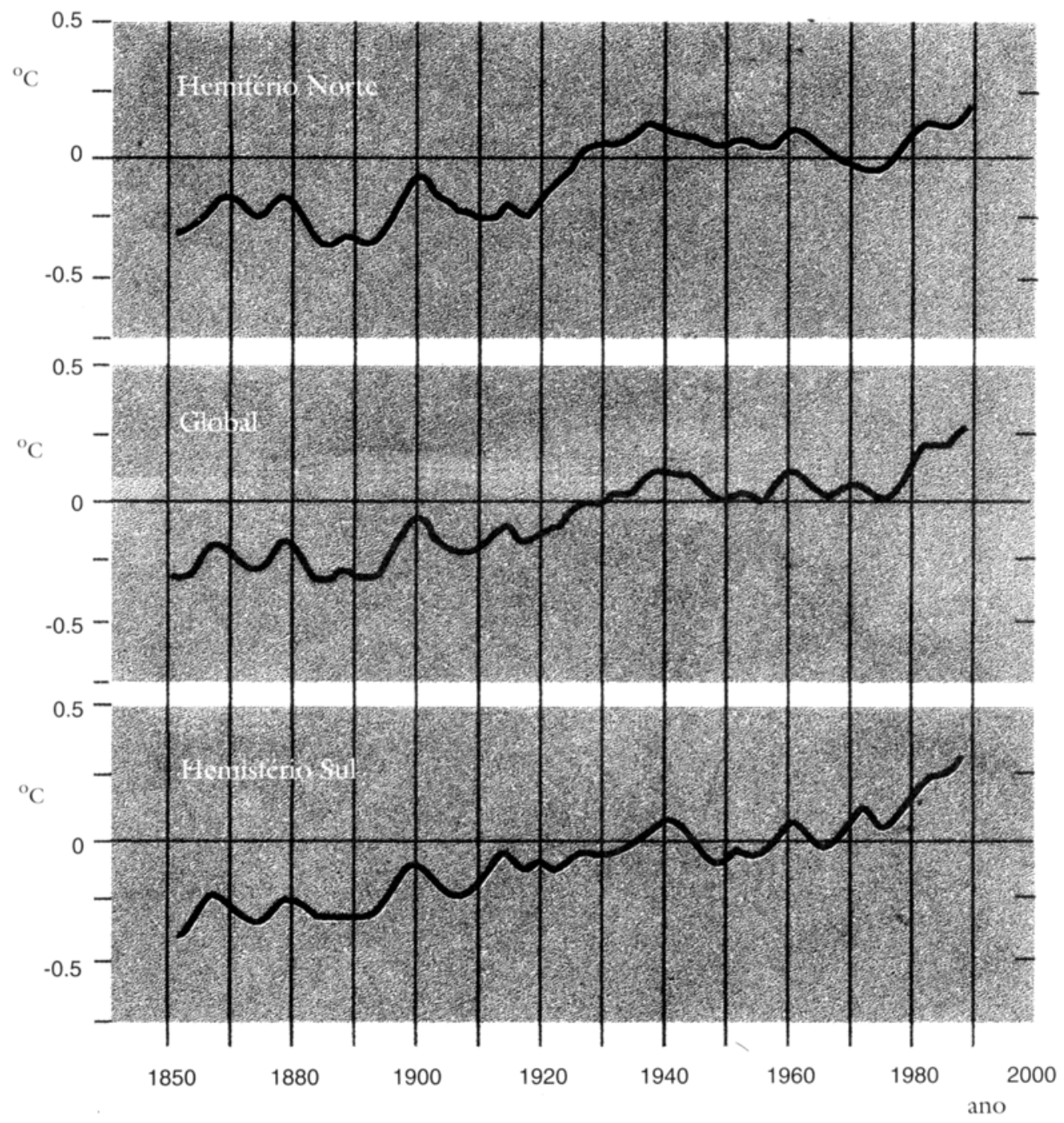

(A média para o período entre 1951 e 1989 foi selecionada como linha 0).

Figura 7: Anomalias de temperatura globais de superfície (1861-1988), levando em conta dados continentais e marítimos

Uma discussão global de tais questões está incluída tanto numa publicação recente das Nações Unidas (5) quanto em outra mais abrangente, no conhecido Relatório da Comissão de Enquete do $11^{\text {th }}$ Parlamento Alemão, particularmente no Relatório de status com a recomendação para uma Nova política de 
energia (v.1) (6) e Protegendo a atmosfera da Terra - um desafio internacional (7).

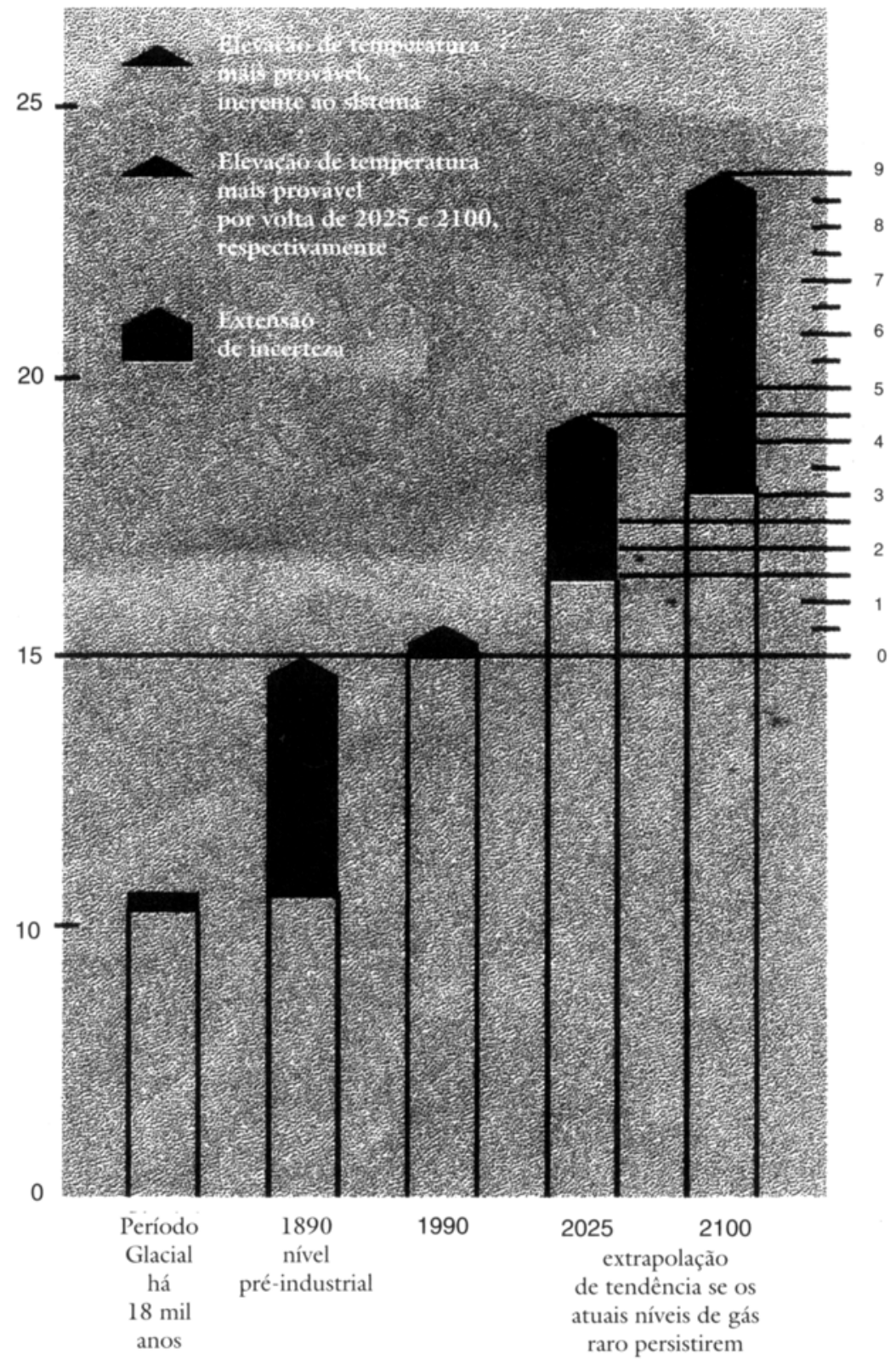

Figura 8

Elevação de temperatura desde o último período glacial

(18 mil anos atrás) e aumentos de temperatura a serem esperados, quando comparados com os níveis pré-industriais, se a tendência atual de emissão de gás raro for explorada até os anos $2025-2100$. 
Há preocupação com a necessidade de se reduzir o atual uso exagerado de energia, particularmente de combustíveis fósseis, com a adoção, por todos os países preocupados, de regulamentos técnicos bem como de severas restrições legais, incluindo maneiras de tributação, discutidas antes e durante a Conferência Rio-92, levando às Convenções sobre a Biodiversidade e sobre a Mudança de Clima, relacionadas com os problemas de desenvolvimento descritos nas assim chamadas recomendações da Agenda 21.

Quero introduzir à discussão da longa lista dos impactos potencialmente danosos da queima dos gases antropogênicos do esfeito estufa, perguntando como o aumento antecipado de poucos graus na temperatura afetaria de alguma forma a mortalidade de nossa espécie.

Essa investigação (8), que foi rapidamente citada na reunião científica da Unesco paralela à Conferência Rio-92, foi motivada por um relatório já existente de observações dos efeitos de ondas de calor incomuns na mortalidade humana.

Nesta comunicação, examinaremos quantativamente os dados publicados por J. P. Besancenot em 1990 sobre a onda de calor que atingiu Marselha em julho-agosto de 1983, os quais são apresentados na figura 9. Como pode ser observado, a mortalidade diária aumentou de 60 mortes por dia em 15 de julho de 1983 para cerca de 100 mortes em 25 de julho, decrescendo finalmente ao patamar normal ( 28 mortes por dia) em 13 de agosto. Testes estatísticos indicam a correlação óbvia entre o aumento da temperatura média e a mortalidade.

A abordagem óbvia ao problema seria investigar se o calor ativou a mortalidade, seguindo alguma lei quantitativa - que auspiciosamente levasse em conta previsões a serem feitas sobre aquecimento similar induzido pela queima de combustível fóssil de estufas. Em particular, uma vez que a mortalidade por calor ativado por unidade de tempo (óbitos/dias) poderia ser tomada como um processo de índice, parece ser razoável conjeturar sobre a obediência à relação Arrhenius.

Os resultados para Marselha encontram-se no figura 10 e mostram claramente que, dentro do âmbito da temperatura relatada, a lei prévia é obtida quantitativamente.

Atualmente, outros relatórios sobre as ondas de calor que afetaram o centro-oeste americano, Londres, e Grécia estão sendo examinados. As energias de ativação observadas parecem razoavelmente típicas de processos bioquímicos, mas há ainda falta de amostras maiores, o que não permite, no momento, a precisão necessária para estimar quantitativamente o efeito global na mortalidade por certo constante aumento de temperaturas. 


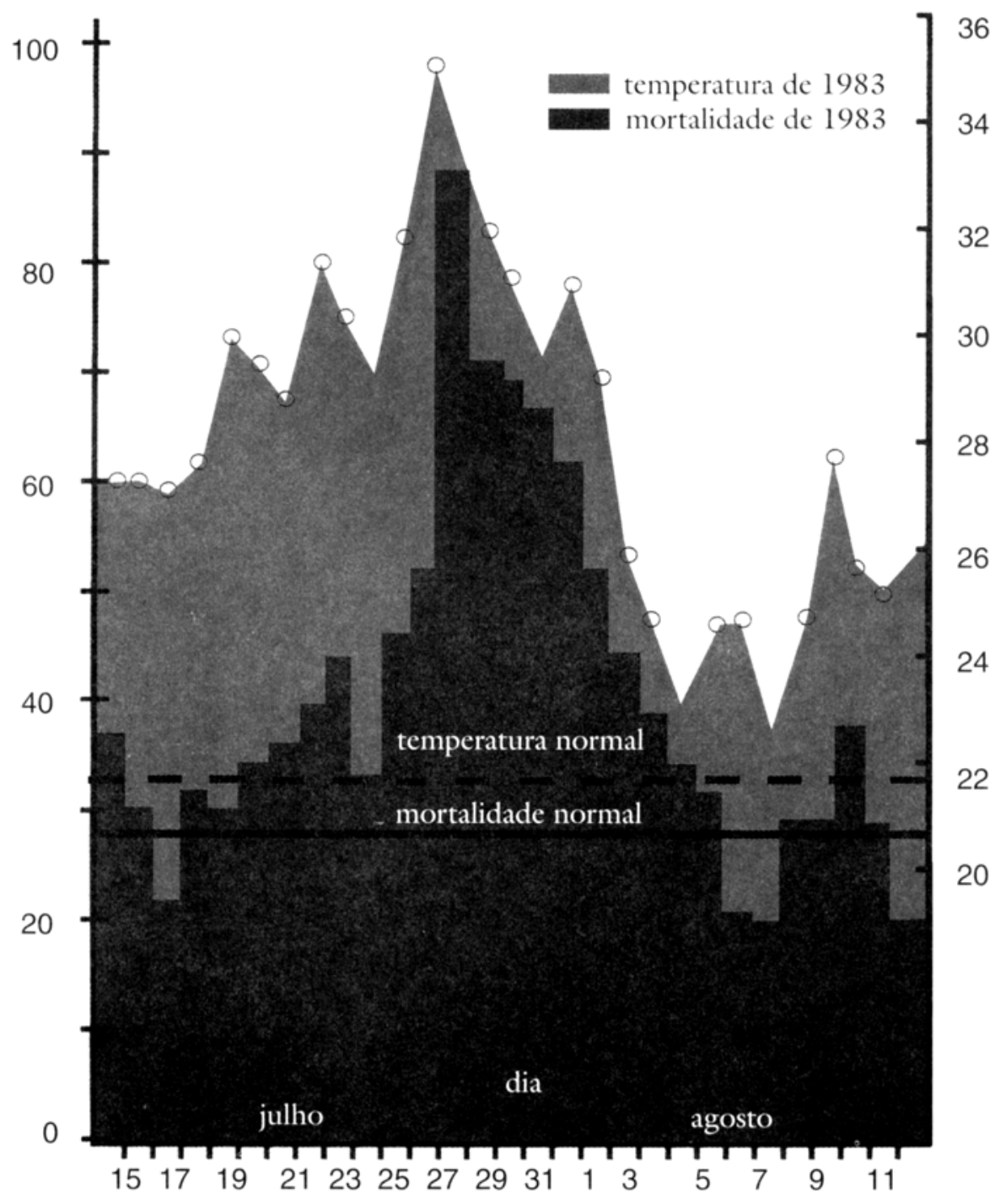

Figura 9: Oscilação de temperatura em Marselha entre julho e agosto de 1983

Estudos confiáveis sobre mortalidade de mamíferos induzida termicamente são infelizmente desconhecidos pelo autor: eles poderiam servir como modelos-guia para pesquisas posteriores. Ademais, a maioria de dados sobre ondas de calor é quase sempre relatada em termos de indices de conforto meteorológicos, sem referência explícita aos valores de temperatura realmente medidos, observados durante a ocorrência dos fenômenos. 


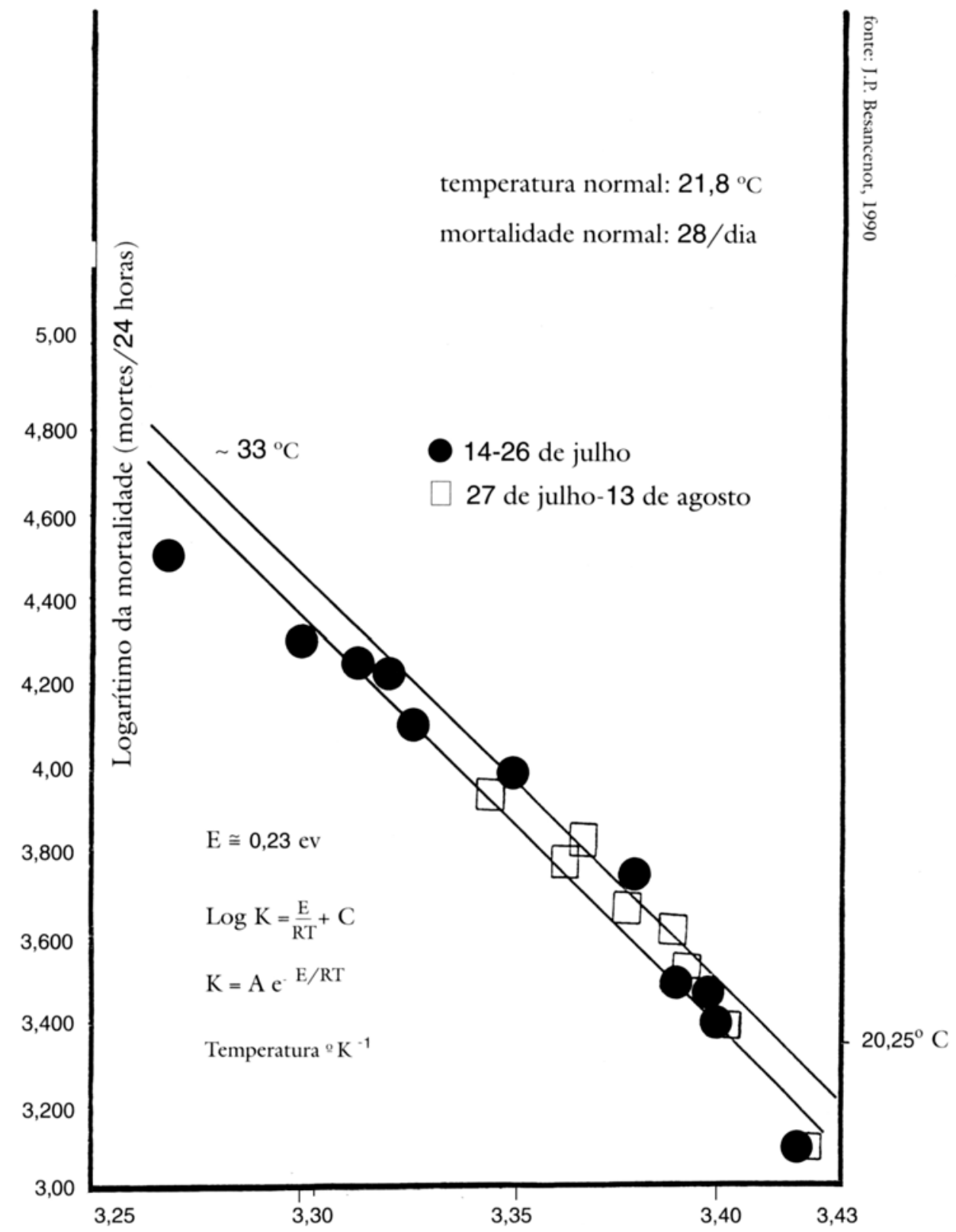

Figura 10

Onda de calor e mortalidade em Marselha entre julho e agosto de 1983

Finalmente, quanto à questão de por quê as temperaturas essencialmente mais altas predominantes nas zonas tórridas não induzem a aumentos evidentes de mortalidade, a resposta parece ser a observação feita pelo próprio Besancenot, de ser pequena a diferença térmica entre noite e dia - ao invés de somente um constante aumento de temperatura - o que poderia explicar os fatos observados. Assim, enquanto Carpentras, perto de Marselha, também sofreu na mesma épo- 
ca temperaturas excepcionalmente altas, o diferencial mais elevado observado, levando em conta noites mais frescas, causou a quase completa imunidade dos habitantes dessa cidade a índices de mortalidade anômalos.

\section{Notas}

1 World Energy Council. Energy for tomorrow's world. New York, St. Martin's Press Inc, 1993.

2 Banco Mundial. Energía: eficiencia y conservación en el mundo en desarrollo. Washington, Banco Mundial, 1993.

3 Hans Peter Dürr. Ecology - challenge to economy from the natural science perspective. Communication to the Annual Meeting of the Brazilian Association for Advancement of Sciences (SBPC), Recife, July, 1993.

4 José Goldemberg. Potential global climate change - the realities. Communication to the World Energy Council, 15 Congress, Madrid, September, 1992.

5 United Nations. Energy systems, environment and development. A reader in Advanced technology assessment system. Issue 6, Autumm, 1991.New York, uN, 1991.

6 German Bundestag. Protecting the earth, a status report with recommendations for a new energy policy. v.1, Bonn, Deutcher Bundestag, 1991.

7 . Protecting the earth's atmosphere: an international challenge. Bonn, Deutcher Bundestag, 1989.

8 José Israel Vargas. The Brazilian energy scenario and the environment: an overview. Rio de Janeiro, CBPF, 1992.

José Israel Vargas, químico, é ministro da Ciência e Tecnologia do Brasil.

Texto apresentado pelo autor no seminário internacional The role of applied science and technology for a sustainable society, realizado no Anfiteatro de Convenções da USP. O evento foi promovido pela Universidade de São Paulo e pelo Instituto Internacional de Instituições Científicas (ICSU) em 11 de outubro de 1993.

Tradução de Martha Steinberg. Revisão de Simone Scholze. O original em inglês Energy as a limiting factor for sustainable development - encontra-se à disposição do leitor no IEA-USP para eventual consulta. 